\title{
Platform Competition in Two-Sided Markets: The Case of Payment Networks
}

\author{
SUJIT CHAKRAVORTI * \\ Economic Research Department, Federal Reserve Bank of Chicago \\ ROBERTO ROSON
}

Economics Department, University of Venice

\begin{abstract}
In this article, we construct a model to study competing payment networks, where networks offer differentiated products in terms of benefits to consumers and merchants. We study market equilibria for a variety of market structures: duopolistic competition and cartel, symmetric and asymmetric networks, and alternative assumptions about consumer preferences. We find that competition unambiguously increases consumer and merchant welfare. We extend this analysis to competition among payment networks providing different payment instruments and find similar results.
\end{abstract}

\section{Introduction}

Two-sided markets are defined as a platform providing goods and services to two distinct end-users where the platform attempts to set the price for each type of end-user to "get both sides on board." Armstrong (2002), Evans (2003), and Rochet and Tirole (2003) suggest various examples of two-sided markets such as yellow pages (advertisers and users), adobe acrobat (creators of documents and readers), and television networks (viewers and advertisers). In this paper, we study an example of a two-sided market payment networks (consumer and merchants).

We extend the literature on payment cards in several directions. We incorporate several features of the payment card industry that have received little attention. First, consumers and merchants have distinct preferences for payment cards. For example, American Express, Discover, MasterCard, and Visa compete for consumers in various dimensions.

\footnotetext{
* Contact author. Economic Research Department, Federal Reserve Bank of Chicago, 230 S. LaSalle Street, Chicago, IL 60604, U.S.A. E-mail: sujit.chakravorti@chi.frb.org. We thank Wilko Bolt, David Evans, Bob Hunt, Michael Katz, Jean-Charles Rochet, Tuomas Takalo, Jean Tirole, and participants at the Economics of Two-Sided Markets conference held at the University of Toulouse, the Economics of Payments conference held at the Federal Reserve Bank of Atlanta, the 2004 International Industrial Economics conference, the 2004 Federal Reserve System Conference on Financial Structure and Regulation, and the Antitrust Activity in Card-Based Payment Systems: Causes and Consequences held at the Federal Reserve Bank of New York for comments on previous drafts. The views expressed are not necessarily those of the Federal Reserve Bank of Chicago or the Federal Reserve System.
} 
Most compete on credit terms such as interest rates, billing cycles, and lines of credit for the consumer side. Card networks also compete for merchants based on fees and benefits such as the type and number of cardholders. Second, payment instruments compete with one another based on consumer and merchant brand preferences. Third, we consider competition among different types of payment instruments. We study the effects on consumer and merchant welfare if two payment networks offering different payment features such as debit and credit cards were owned by one entity or by two different ones.

Our model investigates the pricing strategies of payment networks that maximize the joint profits earned from both types of end-users. Recent investigations of these markets have focused on the determination of various prices including interchange fees, merchant discounts, and retail prices of goods and services within a single payment platform (see Chakravorti and Emmons, 2003, Chakravorti and To, 2003, Rochet and Tirole 2002, Schmalensee 2002, Schwartz and Vincent, 2002, Wright, 2003 and 2004). ${ }^{1}$ Often policy discussions have focused on whether each participant is paying her fair share of the underlying cost of the payment service and the consumer and merchant benefits of competing networks.

Recently, Guthrie and Wright (2003) and Rochet and Tirole (2003) have investigated pricing decisions by payment networks when there are competing payment platforms. We build upon these two models by considering joint distributions for consumer and merchant benefits from participating on each network. In other words, each consumer and merchant is assigned a network-specific level of benefit from participating on each network. Consumers and merchants base their payment network usage decision on the difference between their individual network-specific benefit and that network's participation fee. Our model also differs because we consider the effects of competition on price level and price structure. We consider three types of market structures for payment networks: cartel, noncooperative duopoly under product differentiation, and Bertrand duopoly (price competition for homogeneous products). We find that competition unambiguously improves consumer and merchant welfare while reducing the profits of payment networks. However, neither competition nor cartel market structures yield welfare-efficient price structures.

\section{$2 \quad$ Literature review}

Payment services can be classified as network goods where consumers benefit from greater merchant acceptance and merchants benefit from greater consumer usage. While the literature on network effects is well established (see Farrell and Saloner, 1985 and Katz and Shapiro, 1985), this literature ignores how prices are determined when there are two different groups of consumers where each group of consumers benefits from an increased level of participation by consumers in the other group.

Recently, several papers have investigated price structures in two-sided markets with network effects. Armstrong (2002), Caillaud and Jullien (2001), Jullien (2001), Rochet and Tirole (2003), and Schiff (2003) explore platform competition for various industries. A major contribution of this literature is that different types of end-users may not share equally in the costs of providing the good or service. In some cases, one-type of end-user

\footnotetext{
${ }^{1}$ Interchange fees are payments made by the merchant's financial institution to the consumer's financial institution. Merchant discounts are per-transaction fees paid by merchants to their financial institution.
} 
may be subsidized. Many of the results depend on the accessibility of different types of end-users to different platforms, the underlying fee structure, and their demands for services from a specific platform.

Networks providing payment services are two-sided markets. Rochet and Tirole (2004) state that a necessary condition for a two-sided market is the failure of Coase theorem. A key observation in the market for payment services is that merchants generally charge the same price regardless of the type of payment instrument used to make the purchase. ${ }^{2}$ Furthermore, consumers and merchants seldom negotiate prices based on the cost differences associated with the usage of different payment instruments. However, Rochet and Tirole argue that the failure of Coase theorem is not sufficient for a market to be twosided. They state that for a given price level, if the price structure affects the total volume of transactions on the platform, the market is said to be two-sided.

Most of the payment network literature has only considered a single payment platform. Baxter (1983) models a four-party open network consisting of consumers, merchants, and their respective financial institutions. ${ }^{3}$ Payment providers charge consumers and merchants usage fees. The merchant's financial institution usually pays an interchange fee to the consumer's financial institution. He finds that to balance the demands for payment services by consumers and merchants, an interchange fee may be required to compensate the financial institution that serves the group that benefits less and/or faces higher costs to bring that group on board. Rochet and Tirole (2002), Wright (2003) and (2004) expand on Baxter's analysis by considering the effects of strategic interactions among payment system participants on the determination of the interchange fee.

Rochet and Tirole (2003) consider platform competition generally and investigate some characteristics of payment markets. First, they provide a general framework to model platform competition that is applicable to various markets. Second, they are able to characterize the determinants of price allocation between end-users. There may be instances where one end-user subsidizes the other. Third, they find that the seller's price (could be viewed as the merchant discount in the payment services context) increases with captive buyers (buyers could be viewed as payors in the payments context) and decreases when there are marquee buyers under certain conditions. Similarly, the buyer's price moves in the opposite direction. Captive buyers prefer to use a particular platform and marquee buyers are coveted by sellers.

Guthrie and Wright (2003) also model competing payment networks where merchants use card acceptance as a strategic tool. They assume per-transaction costs for both consumers and merchants and each network's benefit is identical to their competitors. Their main result is that when consumers hold only one card, competition between payment networks does not result in a lower interchange fee. However, if some consumers are able to hold more than one card, equilibrium interchange fees are lower if merchants are monopolists. If merchants compete for customers, merchants are willing to pay higher interchange fees potentially erasing any reduction in interchange fees.

\footnotetext{
${ }^{2}$ The charging of different prices depending on the type of payment instrument used has a long legal and regulatory history in the United States (see Chakravorti and Shah, 2003). Even in countries, where merchants face no restrictions to impose different prices, few merchants choose to do so. Vis and Toth (2000) do not find significant number of Dutch merchants charging prices based on the payment instrument used to make the purchase after the removal of the non-discrimination policies.

${ }^{3}$ In open networks, the network provides services to different downstream financial institutions. These financial institutions compete for consumers and merchants. Whereas in closed or proprietary networks, one entity serves both consumers and merchants and operates the network.
} 
Schiff (2003) explores platform competition in a Cournot duopoly, focusing on the effects of benefit asymmetry for the two sides. He finds that multiple equilibria may occur for some parameter values. He also considers the possibility of having "open systems," where subscribing to a network gives access to all agents on the other side of the market (independent of their network affiliations). In his framework, competing platforms have incentives to make their systems open. ${ }^{4}$

Our model differs from the existing literature in several ways. First, we focus on competing payment networks that offer differentiated payment instruments that have independent benefits and costs for consumers and merchants. In other models, consumers and merchants are indifferent between the benefits of each network. As a result, we are able to compare differences in consumer and merchant preferences for each network's products. Consumers may prefer one network's product over another's based on the types of services offered or the status of being a member. We also consider competition among different types of payment instruments offered by different networks. Consumers not only choose among networks for a type of payment instrument, but also choose among different types of payment instruments. We consider this case as an extension of our model.

Second, we consider the effects of competition on price level and price structure. Rochet and Tirole (2003) assume a small fixed level of profits for both issuing and acquiring sides in a non-profit joint-venture network. In reality, for-profit and non-profit networks coexist in debit and credit card markets. They consider welfare effects of changes in the price structure at a given price level. Similarly, Guthrie and Wright (2003) consider only welfare effects of changes in price structure and not of changes in the price level. In most payment card models, networks maximize profits by maximizing the volume of transactions. This is important because, in many circumstances, social welfare maximization also implies maximizing the volume of transactions. In our model, maximizing profits is not necessarily equivalent to maximizing the volume of transactions potentially resulting in market prices that are not necessarily welfare-efficient.

Third, in our model, each network serves as both issuer and acquirer. Therefore, we do not explicitly model the interchange fee. However, we can implicitly consider interchange fees if acquirers simply pass through their costs to merchants. In other words, issuers set prices for both consumers and merchants.

\section{The model}

We construct a one-period model of payment network competition with three types of agents. There are two payment network operators. There are a large number of consumers and a large number of merchants. Consumers demand one unit of each good and purchase goods from each merchant. ${ }^{5}$

To focus on the choice of payment instrument, consumers and merchants derive utility based on the type of payment instrument used. There are three payment instruments. Cash is the default payment instrument available to all consumers and merchants at zero cost

\footnotetext{
${ }^{4}$ This is equivalent to a special access regime (peering). The economics of peering access is investigated in Little and Wright (2000) and Roson (2003).

${ }^{5}$ While this model specification is quite common in the payment card literature, a more complete model would consider a budget constraint where purchases of underlying goods and services are also considered. Chakravorti and Emmons (2003) and Chakravorti and To (2003) consider such budget constraints.
} 
yielding zero utility for both consumers and merchants. ${ }^{6}$ There are two payment networks each offering a payment product that is associated with positive benefits for most consumers and merchants. These networks may offer similar products such as different types of credit cards or offer different types of instruments such as credit and debit cards. Each network provides services to both consumers and merchants directly and must recover the total cost of providing these services.

The total benefit, obtained by a consumer from being a member of a network, is given by a per-transaction benefit, $h_{i}^{c}$, multiplied by the number of merchants accepting the payment product, $D_{i}^{m}$. For each consumer, per-transaction benefits are independently distributed via a cumulative distribution with support $\left[0, \tau_{i}\right]$, where $i \in\{1,2\}$ is an index referring to the specific payment network. Consumer benefits may include convenience, extension of short-term and long-term credit, security, and status.

Unlike Rochet and Tirole (2003) and Guthrie and Wright (2003), we consider network benefits that are platform-specific. We motivate this difference by observing that different card networks provide different benefits to different consumers. For example, charge cards, instruments where consumers are not allowed to revolve balances, coexist with credit cards, instruments where consumers are allowed to revolve. The pricing structures differ between these two instruments. Charge cards such as American Express cards have traditionally charged higher consumer and merchant fees than Visa and MasterCard cards where issuers earn revenue from finance charges to revolvers. Another example is the coexistence of signature-based and PIN-based debit cards with different price structures. ${ }^{7}$ In our model, we allow some consumers to have strong preferences for a given network's product and allow other consumers to have weaker preferences so that underlying price structures may affect usage decisions.

Without loss of generality, we assume that consumers pay an annual fee, $f_{i}^{c}$, to access the payment system, allowing them to make an unlimited number of payments. ${ }^{8}$ While most U.S. issuers do not impose annual fees, some credit and debit card issuers that offer additional enhancements such as frequent-use awards impose annual fees. Generally, most European issuers impose annual fees. ${ }^{9}$

The assumption that consumers pay fixed fees, while merchants pay on a pertransaction basis, is not crucial. As noted by Rochet and Tirole (2004), when agents have expectations about the number of transactions carried out in equilibrium, there may be redundancy in price instruments: reducing the membership fee, while increasing the per-

\footnotetext{
${ }^{6}$ In reality, the cost of cash transactions and the utility derived from using cash are not zero. The key assumption here is that the cost of cash transactions and the utility derived from using cash is less than that of all other payment instruments. Therefore, costs and benefits can be interpreted as costs and benefits net of cash costs and benefits.

${ }^{7}$ In the United States, there are two types of debit card networks-signature-based cards that use credit card networks to process transactions and PIN-based cards that use the ATM networks to process transactions. These types of transactions have different pricing structures.

${ }^{8}$ Guthrie and Wright (2003) do not consider fixed fees. Rochet and Tirole (2003) consider fixed fees as a special case of their model.

${ }^{9}$ The reason that U.S. issuers do not generally impose annual fees is because of the competitive landscape of U.S. issuers and the unbundling of credit card services from other financial services.
} 
transaction fee appropriately, would not change the global cost faced by each consumer (or merchant), which is the factor driving her adoption choices. ${ }^{10}$

We assume that consumers adopt at most one card (singlehoming). Rysman (2004) finds that while U.S. consumers may hold payment cards from more than one network, the majority of cardholders prefer to use one card. This is equivalent to imposing the following constraint: if $h_{j}^{c} D_{j}^{m}-f_{j}^{c} \geq h_{i}^{c} D_{i}^{m}-f_{i}^{c}$ then $f_{i}^{c} \geq h_{i}^{c} D_{i \neq j}^{m}$ where $D_{i \neq j}^{m}$ is the number of merchants that accept network $i$ 's product but not network $j$ 's. In other words, the additional benefit of holding a second card is less than the fee of holding the card. Since $h_{i}^{c}$ is a consumer-specific parameter, for the condition to hold for all consumers, it must be that: $\tau_{i} \leq f_{i}^{c} / D_{i \neq j}^{m}$. On the other hand, this condition will not hold if the consumer fee is negative. We will discuss below how relaxing this constraint would affect our results, and whether our findings turn out to be consistent with this initial assumption.

Utility from card holding is given by the difference between total benefits from all transactions and the fee. Therefore, the total benefit to consumers increases as merchant acceptance increases. Once a consumer becomes a member of a payment network, we assume the consumer uses that network's payment product exclusively with merchants that accept it. In other words, non-cash purchases dominate cash purchases for those consumers that are members of a payment network. ${ }^{11}$

Each merchant is a monopolist selling a unique good. ${ }^{12}$ Merchant benefits could include security, convenience, and status. Merchants pay a per-transaction fee, $f_{i}^{m}$, but cannot set different prices based on the payment instrument used. ${ }^{13}$ A payment type will be accepted whenever the per-transaction benefit $h_{i}^{m}$ (which is drawn randomly from a cumulative distribution function $G_{i}^{m}$, with support $\left[0, \mu_{i}\right]$ ) exceeds the per-transaction fee. Note that: (1) acceptance choices are independent, and (2) acceptance does not depend on the number of consumers that are members of that payment network whereas a consumer's choice depends on the number of merchants accepting the payment card. ${ }^{14}$ There are three types

\footnotetext{
${ }^{10}$ In a general model, in which both consumers and merchants are free to join any number of networks, Roson (2005) demonstrates that this redundancy emerges only if consumers and merchants do not significantly differentiate themselves in terms of their preferences for each payment platform. In this setting, each network could have four types of customers: singlehoming consumers, multihoming consumers, singlehoming merchants, multihoming merchants. To address each group, four price instruments are available: fixed membership fees (possibly negative) for consumers and merchants, and transaction fees (possibly negative) for consumers and merchants.

${ }^{11}$ Given the marginal cost for card usage is zero and the marginal benefit is positive, consumers will prefer to use this instrument for all transactions. Similar arguments have been made for check usage in the United States, see Chakravorti and McHugh (2002).

${ }^{12}$ Note that by construction, we ignore business stealing effects. Other models, such as Guthrie and Wright (2003), have shown that business stealing incentives may allow network operators to charge higher fees to merchants.

${ }^{13}$ Pricing restrictions on merchants may take various forms. Non-discrimination pricing polices prohibit merchants from setting different prices based on the payment instrument used. In the United States, merchants are allowed to extend discounts for purchases made with non-credit card payment forms. However, card association rules prohibit surcharges for credit card purchases in most jurisdictions although this restriction is facing regulatory pressure in some countries.

${ }^{14}$ Clearly, if merchants are restricted to choosing only one payment network, the number of consumers that are members of a payment network would affect the merchants' choice of networks. This assumption is key in achieving a unique equilibrium. If consumers' and merchants' choices would be interdependent, the
} 
of merchants. Those that accept neither of the payment network's products because the benefit from accepting them is lower than the fee charged. Other merchants will only accept one of the payment network's products because while the net benefit of one network is positive, the other is negative. Finally, some merchants will accept both noncash payment products because there are positive benefits from doing so.

In summary, utility for the representative consumer, $U^{c}$, and merchant, $U^{m}$, can be expressed as:

(1) $U^{c}=\max \left\{0, h_{1}^{c} D_{1}^{m}-f_{1}^{c}, h_{2}^{c} D_{2}^{m}-f_{2}^{c}\right\}$

(2) $U^{m}=\max \left\{0,\left(h_{1}^{m}-f_{1}^{m}\right) D_{1}^{c}\right\}+\max \left\{0,\left(h_{2}^{m}-f_{2}^{m}\right) D_{2}^{c}\right\}$

where $D_{i}^{c}$ is the number of consumers holding network $i$ 's instrument and $D_{i}^{m}$ is the number of merchants accepting network $i$ 's product.

Payment networks face two kinds of costs: a consumer fixed cost, $g_{i}$, and a merchant transaction cost, $c_{i}$. Networks maximize the following:

(3) $\Pi_{i}=\left(f_{i}^{c}-g_{i}\right) D_{i}^{c}+\left(f_{i}^{m}-c_{i}\right) D_{i}^{c} D_{i}^{m}$.

Networks choose simultaneously and non-cooperatively the consumer and merchant fees, taking the other network choices as given (a Nash equilibrium). Timing is as follows:

(i) Consumer and merchant benefits are randomly drawn;

(ii) Networks maximize profits, by choosing $f_{i}^{c}$ and $f_{i}^{m}$;

(iii) Merchants decide which payment forms to accept;

(iv) Consumers decide which payment option to purchase;

(v) Transactions are realized.

The number of accepting merchants is determined, on the basis of the distribution function $K_{i}^{m}$ and the total number of merchants, $M$ :

(4) $D_{i}^{m}=\left(1-K_{i}^{m}\left(f_{i}^{m}\right)\right) M$.

Note that merchants accept non-cash payment alternatives as long as their pertransaction benefit from doing so are greater than their costs. Because merchants only face per-transaction fees, they need only have one consumer using the network's product to accept it as long as the benefit is greater than the cost. Because we are considering atomistic merchants, we do not consider steering strategies. A steering strategy entails refusing one card, not because net transaction benefits are negative for that network, but to

market could exhibit multiple equilibria, as it is typically the case in coordination games (for example, choice of a standard). 
induce consumers to carry an alternative card, for which expected net benefits are higher than those of the refused one.

The consumer side of the market is more complicated. To be chosen, a card has to pass two tests: (1) consumers must derive positive utility, and (2) the utility derived from this payment form must be higher than the other payment form. The market shares can be identified as in figure 1, where each consumer is mapped to a point, whose coordinates $\left(h_{i}^{c} D_{i}^{m}, h_{j}^{c} D_{j}^{m}\right)$ express total potential benefits from using card $i$ or $j$.



\section{Figure 1: Network's share of consumers}

In figure 1, the large rectangle is divided into six parts. Consumers falling inside the smaller rectangle in the bottom left do not join either payment network, as their benefits are smaller than the membership fees of either network. Other consumers become members of either payment network $i$ if in rectangle $B$ or payment network $j$ if in rectangle $A$. When both networks are associated with positive utility, consumers choose on the basis of relative utility, and the border between the two market areas is given by the 45 degree segment that splits the square into triangles $C$ and $D$. Consumers in area $E$ also choose a network on the basis of relative utility, but their choice is primarily determined by the number of accepting merchants. For this reason, only the network offering the highest consumer surplus, $\left(\tau D^{m}-f^{c}\right)$, attracts consumers in an area like $E$, which is absent if networks are symmetric and apply equal prices to both consumers and merchants.

Assuming uniform and independent random variables for consumer benefits for each payment product, the consumer demand for each network where $C$ is the total number of consumers can be written as:

$$
D_{i}^{c}=\frac{\left(m_{i}-f_{i}^{c}\right) f_{j}^{c}+.5 w^{2}+\left(m_{i}-f_{i}^{c}-w\right) w}{m_{i} m_{j}} C
$$

and 
(6) $D_{j}^{c}=\frac{\left(m_{j}-f_{j}^{c}\right) f_{i}^{c}+.5 w^{2}+\left(m_{j}-f_{j}^{c}-w\right) w}{m_{i} m_{j}} C$

where:

$$
\begin{gathered}
w=\min \left\{m_{i}-f_{i}^{c}, m_{j}-f_{j}^{c}\right\} \\
m_{i}=\tau_{i} D_{i}^{m} \\
m_{j}=\tau_{j} D_{j}^{m}
\end{gathered}
$$

\subsection{Profit maximization}

When choosing the consumer and merchant fees, $f_{i}^{c}$ and $f_{i}^{m}$, each payment network maximizes profits, given by equation (3). It may be shown that optimal fees obey the following principle:

Lemma 1: Profit maximizing fees are determined by a "modified Lerner rule" that is:

(7) $p^{c}+f^{m}-c=\frac{p^{c}}{\varepsilon^{c}}=\frac{f^{m}}{\varepsilon^{m}+\varepsilon^{c m}-\varepsilon^{m} \varepsilon^{c}}$

where $p^{c}=\frac{f^{c}-g}{D^{m}}$ is the per-transaction revenue minus cost from serving a consumer, and:

$$
\begin{aligned}
\varepsilon^{c} & =-\frac{\partial D^{c}}{\partial p^{c}} \frac{p^{c}}{D^{c}}=\frac{\partial D^{c}}{\partial f^{c}} \frac{\left(f^{c}-g\right)}{D^{c}} \\
\varepsilon^{c m} & =-\frac{\partial D^{c}}{\partial f^{m}} \frac{f^{m}}{D^{c}} \\
\varepsilon^{m} & =-\frac{\partial D^{m}}{\partial f^{m}} \frac{f^{m}}{D^{m}}
\end{aligned}
$$

Proof: Following Rochet and Tirole (2003), substitute into equation (3), and consider the following problem:

(8) $\max _{p_{i}^{c}, f_{i}^{m}} \log \left(\Pi_{i}\right)=\log \left(p_{i}^{c}+f_{i}^{m}-c_{i}\right)+\log \left(D_{i}^{c}\right)+\log \left(D_{i}^{m}\right)$.

Assuming log-concavity, equation (7) is obtained from simple manipulations of firstorder conditions of the maximization problem (8), observing that:

$$
\frac{\partial p^{c}}{\partial f^{m}}=-\frac{\left(f^{c}-g\right)}{\left(D^{m}\right)^{2}} \frac{\partial D^{m}}{\partial f^{m}}=\frac{p^{c}}{f^{m}} \varepsilon^{m}
$$

Lemma 1 highlights that the problem of setting optimal fees can be decomposed in two parts: the choice of the global price level, $p_{i}^{c}+f_{i}^{m}$, and the problem of balancing the relative prices, $p_{i}^{c} / f_{i}^{m}$. The result does not depend on specific assumptions about benefit distributions. 
This result is an adaptation of a finding obtained by Rochet and Tirole (2003), who derived first order general conditions for profit maximization in a two-sided market. In deriving these conditions, however, they ignored the effect of a variation in network size on the price level. Equation (7) translates the result of Rochet and Tirole for our case, while taking into account the effect of network size on the consumer price.

\subsection{The effects of competition on prices and welfare}

To see how competition affects the market equilibrium, we now consider two cases: a duopoly, where each network maximizes its profits, assuming the competitor's fees as given, and a monopoly, where a hypothetical cartel maximizes the sum of the two networks' profits. The difference between the two cases is given by the fact that a monopolist internalizes any pecuniary externality, that is, any effect of a price change in the other operator's profit. In other words, the cartel maximizes the sum of the two profit functions, as defined in equation (3). Furthermore, as the following proposition states, pecuniary externalities have an unambiguous effect on the price level and welfare.

Proposition 1: In the market for payment services defined above, equilibrium prices for both consumers and merchants are lower, or at least not higher, in duopoly than in the monopolistic cartel. Lower consumer fees increase consumer welfare and, indirectly, merchant welfare because of the higher number of consumers in a network. Lower merchant fees increase merchant welfare and, indirectly, consumer welfare because of the higher number of merchants in a network.

Proof: Since the number of subscribing merchants is unaffected by the other network prices, cross-effects on profits only operate through changes in the consumers' demand volume:

$$
\begin{aligned}
& \frac{\partial \Pi_{i}}{\partial f_{j}^{c}}=\left(f_{i}^{c}-g\right) \frac{\partial D_{i}^{c}}{\partial f_{j}^{c}}+\left(f_{i}^{m}-c\right) D_{i}^{m} \frac{\partial D_{i}^{c}}{\partial f_{j}^{c}}=\frac{\Pi_{i}}{D_{i}^{c}} \frac{\partial D_{i}^{c}}{\partial f_{j}^{c}} \geq 0 \\
& \frac{\partial \Pi_{i}}{\partial f_{j}^{m}}=\left(f_{i}^{c}-g\right) \frac{\partial D_{i}^{c}}{\partial f_{j}^{m}}+\left(f_{i}^{m}-c\right) D_{i}^{m} \frac{\partial D_{i}^{c}}{\partial f_{j}^{m}}=\frac{\Pi_{i}}{D_{i}^{c}} \frac{\partial D_{i}^{c}}{\partial D_{j}^{m}} \frac{\partial D_{j}^{m}}{\partial f_{j}^{m}} \geq 0
\end{aligned}
$$

where the sign of both relationships is obtained from the definitions of utility (1) and (2).

A decrease in either merchant or consumer fees, applied by the competitor network, reduces the consumer demand and a network profit. This negative pecuniary externality is internalized by the monopolistic cartel, but not by the duopolistic competitors. As a consequence, the cartel will set higher prices than in the duopoly. In other words, the perceived price elasticity of a competitive network will always be larger than that of a monopolistic cartel, so that competition brings about lower merchant and consumer fees.

In the model with uniform and independent distributions for consumer and merchant benefits, cross price derivatives (and elasticities) are discontinuous at one point, but they can be written in a compact way. Using the notation introduced above:

(10) $\frac{\partial D_{i}^{c}}{\partial f_{j}^{c}}=\frac{w}{m_{i} m_{j}} C>0$ 


$$
\begin{aligned}
\frac{\partial D_{i}^{c}}{\partial f_{j}^{m}} & =\frac{\partial D_{i}^{c}}{\partial m_{j}} \frac{\partial m_{j}}{\partial f_{j}^{m}} \\
& =\left(\frac{m_{i}-f_{i}^{c}-w}{m_{i} m_{j}}-\frac{D_{i}^{c}}{m_{j}}\right) \frac{-\tau_{j}}{\mu_{j}} C M \\
& =\left\{\begin{array}{l}
\frac{D_{i}^{c}}{m_{j}} \frac{\tau_{j}}{\mu_{j}} C M>0 \\
o r \\
\frac{\left(m_{j}\right)^{2}-\left(f_{j}^{c}\right)^{2}}{2 m_{i}\left(m_{j}\right)^{2}} \frac{\tau_{j}}{\mu_{j}} C M>0
\end{array}\right.
\end{aligned}
$$

Proposition 1 has a simple intuitive explanation. A two-sided network has two instruments to attract more consumers: the prices applied to consumers and merchants. Both instruments, however, work to the same direction, expanding one network and reducing the competitor's one. Despite the existence of two price instruments, pecuniary externalities work in the standard way.

This finding, intuitive as it may seem, is actually in sharp contrast with most recent literature on competition in credit card networks (for example, Rochet and Tirole, 2002 and Guthrie and Wright 2003), where it is shown that competition may be harmful for consumers and merchants. The key difference between our approach and the previous literature is that the latter is based on the (sometimes implicit) assumption of constant profits for the financial institutions of consumers and merchants and often a zero profit condition for the network. In our model, network profits decrease with competition. Below, we will consider changes to the price ratio holding profits constant.

If profits are constant for payment providers (in our case, the networks), the main effect of competition is altering the price balance between the two sides of the market. However, we will show below the equilibrium price structure is generally not welfareefficient for duopolistic competition or monopolistic cartel. In both cases, it would be possible to achieve higher aggregate welfare by reducing the price on one side, while increasing the price on the other side, so as to keep global network profits unchanged. The move from monopoly to competitive duopoly may not help in this sense. However, if profits are unconstrained, the overall price reduction dominates the effects on the price structure and welfare unambiguously improves for both sides.

It should be stressed that we retain the existence of two alternative platforms, even in the monopolistic setting. On the contrary, Schiff (2003) considers a monopoly with a single platform, finding that welfare may improve when switching from duopolistic competition to monopoly. Prices actually increase, but a single standard is imposed, which is beneficial in the presence of network externalities. This result may not hold in our model, however, because we consider network-specific preferences. Therefore, like in a monopolistic competition model, the trade-off between economies of scale and "taste for variety" should be taken into account. 
Another point worth noting is the persistence of profits in the duopolistic equilibrium. This is a consequence of platform heterogeneity. We discuss a model variant below, where we consider perfect correlation in the distribution of platform benefits. In that case, each platform has a greater incentive to undercut its competitor, by reducing one of the two fees.

\subsection{Symmetric competition}

If networks are perfectly symmetric, equilibrium fees, in all market structures, must be equal. Guthrie and Wright (2003) consider some cases of symmetric competition between payment platforms. They focus solely on the price balance effect of competition, because they consider either a bank association with fixed margins on the two market sides, or proprietary schemes subject to Bertrand-like competition, dissipating profits. This implies that, in their model, total revenue is constant in all market structures.

In our model, market competition reduces the total price, the sum of the consumer and merchant fees, and increases merchant and consumer welfare. However, the price reduction is not, in general, uniform in the two sub-markets. To see this, consider the effects of a reduction in merchant and consumer fees on the other network's demand volume. Figure 2 provides a graphical illustration of changes in market sizes generated by a reduction of consumer fee, whereas figure 3 provides a representation of the effects of a merchant fee reduction resulting in greater merchant acceptance.

When the consumer fee is reduced in a network, the network's demand expands because some new customers are convinced to choose this platform. Among these customers, some were not subscribing to any card before, whereas some others are now switching from the other network.

A reduction in a merchant fee, on the other hand, has an indirect effect on the other network demand. A reduction in the merchant fee affects the merchant's demand, which in turn affects the consumer's demand: shifts outward. The area corresponding to the competing network's market share does not change, but the density of the consumers in the rectangle decreases.

Because of this "stretching effect" some consumers, previously associated with points slightly to the left of the 45 degree segment in figure 3, are now found to the right of this dividing line, in another market area. ${ }^{15}$ These consumers are switching to the alternative network, not because consumer fees are lower there, but because there is a larger base of accepting merchants.

Note that for the merchants' side of the market, the two networks are independent: no merchant customer is lost if the degree of acceptance for the competitor network has increased. The two networks are actually fighting to conquer the consumers' side of the market (the singlehoming side). Therefore, merchant fees are strategic instruments because they allow networks to entice more consumers (indirectly) to join the network.

In a monopolistic two-sided market, a network operator selects prices to balance the two sides of the market (to get both sides on board). Under competition, the pricing pressure may be different in the two sub-markets, and the price structure, which emerges in equilibrium, depends on the different market conditions. In other words, competition does not simply drive both prices down, but also alters the balance of prices.

\footnotetext{
${ }^{15}$ Also, some previous non-subscribers, initially in the smaller lower left rectangle, are moved rightward into the market area.
} 


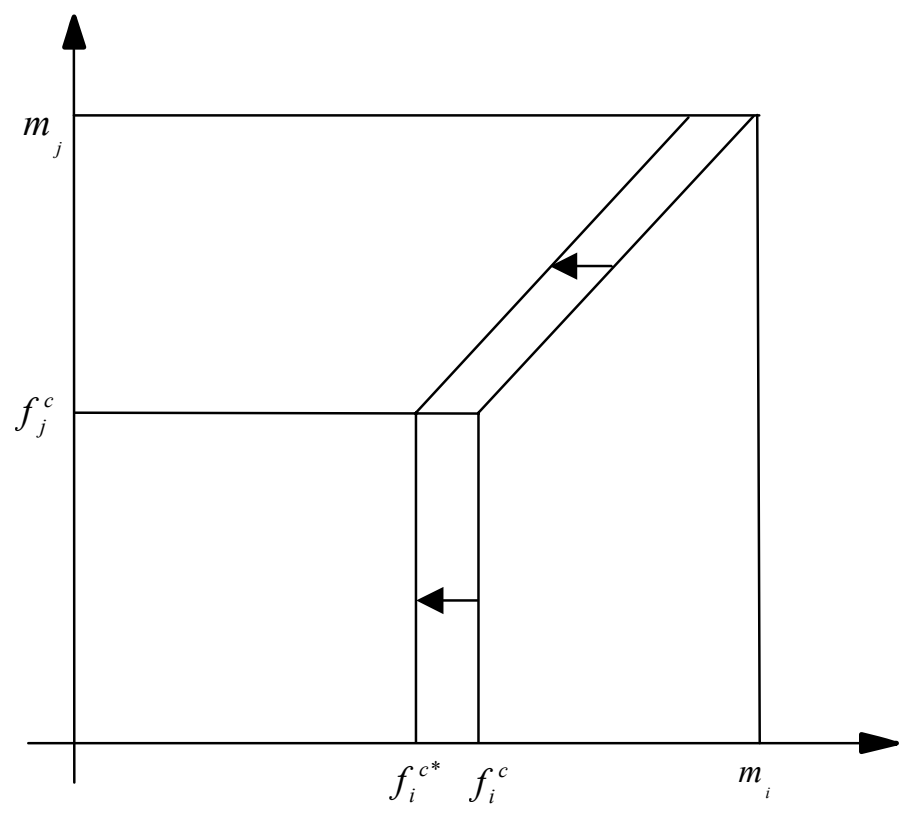

Figure 2: Market share effects of a reduction in a consumer fee

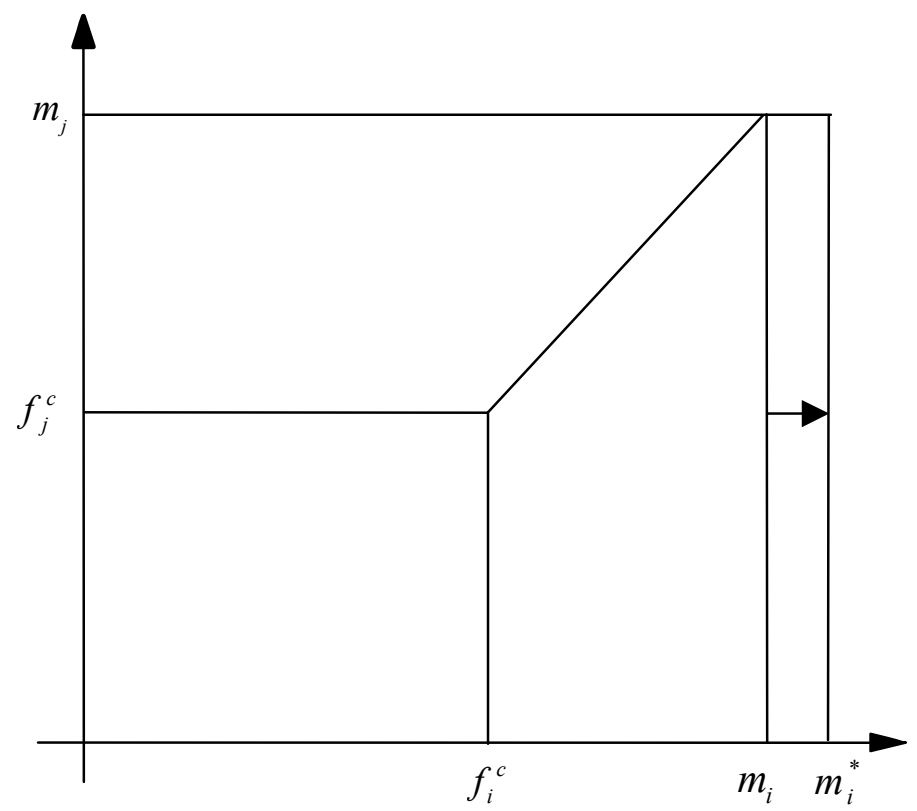

Figure 3: Market share effects of a reduction in a merchant fee

According to the optimality condition (equation 7), price levels and structure depends on demand elasticities. Elasticities are all higher under competition, so the question is whether some elasticity parameters display relatively larger differences when switching from monopoly to duopoly. For example, if the own-price elasticity of consumer demand $\left(\varepsilon_{i}^{c}\right)$ varies very much, this would call for a strong reduction in consumer fees.

The degree of sensitivity to price changes is linked to the density of the benefits distribution which, in the uniform case, amounts to $1 / \tau$ for consumers and $1 / \mu$ for merchants. Like in a Hotelling model, the denser the distribution (low $\tau$ or $\mu$ ), the higher 
the demand sensitivity to price changes, bringing about strong competitive pressure and low prices in equilibrium. ${ }^{16}$

We provide numerical examples of various equilibria to demonstrate relationships between different market structures. Table 1 presents parameter values, equilibrium fees, network profits, consumer and merchant demand, and total transaction volumes for a series of symmetric duopolistic and monopolistic market equilibria. The first four columns give parameter values: customer fixed costs, transaction costs, upper end of the merchant benefits distribution, and upper end of the consumer benefits distribution. The parameters are not indexed, because they are identical for both networks. The subsequent four columns give equilibrium values for consumer and merchant fees, their difference, and equilibrium profits. The next three columns show each network's demand volume for consumers and merchants and its total non-cash transactions.

Duopolistic

\begin{tabular}{|c|c|c|c|c|c|c|c|c|c|c|}
\hline$g$ & $c$ & $\mu$ & $\tau$ & $f^{c}$ & $f^{m}$ & $f^{c}-f^{m}$ & $\Pi$ & $D^{c}$ & $D^{m}$ & $D^{c} D^{m}$ \\
\hline 0 & 0 & 1 & 1 & .181 & .236 & -.055 & .170 & .471 & .764 & .360 \\
\hline 0 & 0.5 & 1 & 1 & .248 & .449 & -.201 & .087 & .397 & .551 & .219 \\
\hline 0.2 & 0 & 1 & 1 & .360 & .199 & .161 & .127 & .398 & .801 & .319 \\
\hline 0 & 0 & 2 & 1 & 0 & .666 & -.666 & .222 & .5 & .667 & .333 \\
\hline 0 & 0 & 1 & 2 & .828 & 0 & .828 & .343 & .414 & 1 & .414 \\
\hline
\end{tabular}

\begin{tabular}{|c|c|c|c|c|c|c|c|c|c|c|}
\hline$g$ & $c$ & $\mu$ & $\tau$ & $f^{c}$ & $f^{m}$ & $f^{c}-f^{m}$ & $\Pi$ & $D^{c}$ & $D^{m}$ & $D^{c} D^{m}$ \\
\hline 0 & 0 & 1 & 1 & .376 & .248 & .128 & .211 & .375 & .752 & .282 \\
\hline 0 & 0.5 & 1 & 1 & .326 & .451 & -.125 & .096 & .324 & .549 & .178 \\
\hline 0.2 & 0 & 1 & 1 & .474 & .202 & .272 & .141 & .324 & .798 & .259 \\
\hline 0 & 0 & 2 & 1 & .218 & .813 & -.595 & .302 & .433 & .594 & .257 \\
\hline 0 & 0 & 1 & 2 & 1.155 & 0 & 1.155 & .385 & .333 & 1 & .333 \\
\hline
\end{tabular}

Table 1: Symmetric competition

Table 1A shows equilibrium values for each firm under duopolistic Nash competition and table 1B shows equilibrium values of each firm when the two firms operate as a cartel. The results show that for all parameter values the duopolistic competition results in lower consumer and merchant fees (constrained to be non-negative), higher consumer and merchant demand and a greater number of total transactions.

We can check whether these price values are consistent with the initial assumption of consumers joining only one network. It can be verified that this is the case for all scenarios, except for the fourth one. In this setting, it can be shown that $D_{i \neq j}^{m}=D^{m}\left(1-D^{m}\right)$. This has a maximum value of .25. If $f^{c}>.25$ and $\tau=1$ the condition $\tau_{j} \leq f_{j}^{c} / D_{i \neq j}^{m}$ is satisfied. This occurs in all monopolistic equilibria, except for the fourth one. It can be verified that the condition is also satisfied (or not satisfied) in the

\footnotetext{
${ }^{16}$ In other words, the balance is driven by the relative price elasticities of the two types of end-users, defined in terms of consumer or merchant fees. Expressions for these elasticities can be directly derived from equations (10) and (11).
} 
corresponding duopolistic equilibria. Therefore, the latter identifies a market equilibrium in which consumers are forced to singlehome.

There are two cases where either the consumer fee or the merchant fee is zero in the duopolistic market. As expected from our previous discussion, this is a consequence of $\mu<<\tau$ or $\mu>>\tau$, making one side of the market significantly more competitive than the other.

The fee for merchants does not significantly change in the two market structures. However, the fees to consumers changes drastically from duopoly to cartel. In column 7 , we compute the difference between consumer fees and merchant fees, and we find that the difference increases for all parameter values.

The intuitive reason why consumers gain from competition relatively more, in our examples, was provided earlier in terms of changes in elasticity parameters. This result is now formally stated in the following proposition.

Proposition 2: In the symmetric market with uniform and independent distributions of consumer and merchant benefits, there is more competitive pressure on the consumer side (higher marginal profits from a fee reduction) if, in the monopolistic equilibrium, either the merchant fee is zero, or:

(12) $\frac{M f^{c}}{D^{m}} \leq 2 \mu-\tau$.

Proof: Assume $f_{j}^{m}>0$. Starting from a symmetric equilibrium, suppose that either $f_{j}^{c}$ or $f_{j}^{m}$ are marginally decreasing. In both cases, $w=m_{i}-f_{i}^{c}$. Using this value for $w$ in equations (10) and (11), we find that the marginal change in the consumer demand of the competing network, determining the pecuniary externality on profits (and the relative competitive pressure), is higher for the variation in consumer fees if:

$$
\left|\frac{\partial D_{i}^{c}}{\partial f_{j}^{c}}\right| \geq\left|\frac{\partial D_{i}^{c}}{\partial f_{j}^{m}}\right| \Rightarrow \frac{m-f^{c}}{m} \geq \frac{\tau M}{\mu} \frac{\left(m-f^{c}\right)\left(f^{c}+.5\left(m-f^{c}\right)\right)}{m^{2}}
$$

We dropped subscripts, for notational convenience, and we made use of the definition of demand (5) or (6). Condition (12) is obtained from manipulations of condition (13).

On the contrary, assume $f_{j}^{m}=0$. In this case, the partial derivative of the consumer demand is discontinuous, because all merchants are already subscribing to both networks, and a further reduction in the merchant fee would not bring about more merchants and, consequently, more consumers. The networks are therefore competing on one side only (the consumer one), and only consumer fees can decrease.

Observing that consumer fees cannot be negative in the cartel equilibrium, the following corollary can be immediately derived: ${ }^{17}$

\footnotetext{
${ }^{17}$ If $f^{c}=0$ for both networks, all consumers subscribe to one network. Lower fees cannot increase total consumer demand or profits. On the other hand, negative fees could be observed in the competitive duopoly, because of the desire to undercut the competitor.
} 
Corollary 1: A sufficient condition for the consumer fees falling less than merchant fees under competition, if merchant fees remain strictly positive, is:

(14) $\tau \geq 2 \mu$.

The interpretation of condition (14) is clear. If the support of a distribution function is larger, there is more differentiation among agents. When $\tau \geq 2 \mu$, a marginal change in the consumer fee produces little effects on the consumer demand, but a marginal change in the merchant fee produces relatively large variations in the merchant demand. As a consequence, the two networks compete more vigorously on the merchant sub-market, and merchant fees decrease relatively more.

\subsection{The welfare-efficient price allocation}

Although competition improves welfare because of a reduction in total price, competition may not bring about better price structures, in terms of aggregate welfare of consumers and merchants. We show this by using parameter values and prices of Table 1. Platform profits have been defined as:

(15) $\Pi=\left(f^{c}-g\right) D^{c}+\left(f^{m}-c\right) D^{c} D^{m}$.

Keeping the profit level fixed, a marginal change in the consumer fee would be compensated by a marginal change in the merchant fee if:

(16) $\frac{\delta f^{c}}{D^{m}}=-\delta f^{m}$.

Starting from any of the equilibria reported in Table 1, would it be possible to attain a higher level of aggregate welfare for consumers and merchants at the same level of platform profits? To answer this question, we need first to identify the consumer and merchant welfare in the symmetric equilibria. For each single platform, aggregate consumer welfare $(\mathrm{CW})$ and aggregate merchant welfare $(\mathrm{MW})$ are given, in the symmetric case, by:

$$
\begin{aligned}
& M W=\int_{f^{c}}^{\mu}\left(h-f^{m}\right) D^{c} d h \\
& C W=\int_{0}^{f^{c}}\left(\int_{f^{c}}^{m}\left(h-f^{c}\right) d h\right) d k+\int_{f^{c}}^{m}\left(\int_{k}^{m}\left(h-f^{c}\right) d h\right) d k
\end{aligned}
$$

where $m=\tau D^{m}$. Assuming a uniform distribution, yields:

$$
C W=\frac{1}{\left(\tau D^{m}\right)^{2}}\left(\frac{\left(\tau D^{m}-f^{c}\right)^{2} f^{c}}{2}+\frac{\left(\tau D^{m}-f^{c}\right)^{3}}{6}\right)
$$


(20) $M W=D^{c}\left(\frac{\left(\mu-f^{m}\right)^{2}}{2 \mu}\right)$.

To assess the welfare impact of a profit-neutral price rebalancing between the two market sides, we construct the following index: ${ }^{18}$

$$
\eta=\left(\frac{\partial C W}{\partial f^{c}}+\frac{\partial M W}{\partial f^{c}}\right) D^{m}-\left(\frac{\partial C W}{\partial f^{m}}+\frac{\partial M W}{\partial f^{m}}\right)
$$

A positive $\eta$ means that it would be possible to get a higher aggregate welfare (consumer welfare + merchant welfare), by slightly increasing $f^{c}$, while reducing $f^{m}$ so as to keep profits unchanged. The computation of $\eta$ for parameter values and prices of Table 1 gives the results reported in Table 2 for duopolistic competition $(C)$ and monopolistic cartel $(M)$.

\begin{tabular}{|c|c|c|c|c|c|}
\hline$g$ & $c$ & $\mu$ & $\tau$ & $\eta-C$ & $\eta-M$ \\
\hline 0 & 0 & 1 & 1 & 0.361 & 0.255 \\
\hline 0 & 0.5 & 1 & 1 & 0.278 & 0.256 \\
\hline 0.2 & 0 & 1 & 1 & 0.265 & 0.221 \\
\hline 0 & 0 & 2 & 1 & 0.417 & 0.130 \\
\hline 0 & 0 & 1 & 2 & 0.564 & 0.522 \\
\hline
\end{tabular}

Table 2: The efficiency index in market equilibria of Table 1

Note that: (1) the $\eta$ index is always positive, indicating that consumer fees are too low, and (2) introducing competition actually worsens the price structure. This is a direct consequence of consumer fees falling relatively more in the competitive regime. As pointed out in the previous section, this effect may or may not occur depending on parameter values.

Therefore, market competition implies a downward pressure on prices, associated with a change in the price structure. The first effect is welfare-improving, whereas the second one may have negative welfare consequences. In our setting, the first effect dominates the second one, so that both consumers and merchants are better off in any case.

Other models on two-sided markets find that competition may be harmful because of a less efficient price structure. In those settings, this structural effect typically dominates the price level, because the market power of the monopolistic network is already constrained by other factors such as the non-profit nature of the platform and fixed profits for both issuers and acquirers.

\footnotetext{
${ }^{18}$ To keep profits unchanged, an increase (decrease) in $f^{m}$ must be associated with a proportional decrease (increase) in $f^{c}$ by a factor $D^{m}$.
} 


\subsection{Asymmetric competition}

Most real markets involve competition between asymmetric players. For example, debit and credit cards are competing payment instruments, although they differ in terms of cost structure and services provided to consumers and merchants. Such competition has been investigated by the courts in the United States and by regulators in other parts of the world. We are not aware of any theoretical model that has attempted to investigate such competition.

Unfortunately, the analysis of asymmetric competition in our model is very complex and general analytical results cannot be readily obtained. However, useful insights can be gained through a combination of numerical examples and a careful inspection of the optimization condition (7), which still holds, in general, under asymmetry. Furthermore, Proposition 1 does not depend on symmetry assumptions: competition unambiguously improves welfare on both sides, even in an asymmetric market. This is because pecuniary externalities among networks remain negative, and competitive networks fail in internalizing them, thereby setting prices too low (from the point of view of profit maximization).

A simple way to address the issue is to start from a symmetric equilibrium and consider a marginal change in a specific cost or demand parameter, for one of the two networks. How will this perturbation of symmetry conditions affect the market equilibrium? This question can usefully be decomposed into two parts: (a) how will this change induce different aggregate price levels? (b) how will asymmetric conditions affect the balance between relative prices on the two sides of the market?

The first sub-question has a quite straightforward answer. The model considered here is reminiscent of an asymmetric Hotelling model with similar results. In an asymmetric Hotelling duopoly, consumers are evenly distributed along a $[0,1]$ segment, with one firm located at point 0 and the other one located at point $1+\Delta$. Consumers buy one unit of a good from the firm associated with the minimum total cost, which is the sum of producer price and transportation cost. In this case, it can be easily shown that (under full market coverage) prices applied by the first firm (and profits) are an increasing function of the parameter $\Delta$, whereas the opposite occurs for the competitor. Analogously, in our model any cost increase, or any positive change in consumer/merchant preferences, will induce higher (aggregate) prices by a firm and a reaction by its competitor, which lowers its own (aggregate) prices.

In addition, the price balance between the two market sides also changes, because elasticities in equation (7) vary. Rochet and Tirole (2004) note that this effect can be explained by a simple "topsy-turvy principle:" a factor that is conducive to a high price on one side, to the extent that it raises the platform's margin on that side, tends also to call for a low price on the other side, as attracting members on that other side becomes more profitable. Because the relevant cost concept in a two-sided market is the opportunity cost, any time an additional marginal unit is produced on one side, the network faces a marginal cost, but it can also raise the price on the other side, as the utility of the other side agents is increasing.

Coupling this effect with the asymmetric Hotelling one, we can see that any factor that is conducive to a high price on one side for one network induces: (a) a lower price on the other side for the same network, (b) a lower price on the same side for the other network, (c) a higher price on the other side for the other network. In other words, the networks follow opposite strategies in terms of price balancing. 
Duopoly

Network 1

\begin{tabular}{|c|c|c|c|c|c|c|c|c|c|c|}
\hline$g$ & $c$ & $\mu$ & $\tau$ & $f^{c}$ & $f^{m}$ & $f^{c}-f^{m}$ & $\Pi$ & $D^{c}$ & $D^{m}$ & $D^{c} D^{m}$ \\
\hline 0.1 & 0 & 1 & 1.1 & .328 & .176 & .152 & .153 & .410 & .824 & .338 \\
\hline 0.1 & 0.5 & 1 & 1.1 & .397 & .372 & .025 & .068 & .312 & .628 & .196 \\
\hline 0.1 & 0 & 1.1 & 1.1 & .285 & .235 & .050 & .158 & .427 & .786 & .336 \\
\hline 0.1 & 0.5 & 1.1 & 1.1 & .363 & .434 & -.071 & .075 & .335 & .605 & .203 \\
\hline
\end{tabular}

Network 2

\begin{tabular}{|c|c|c|c|c|c|c|c|c|c|c|}
\hline$g$ & $c$ & $\mu$ & $\tau$ & $f^{c}$ & $f^{m}$ & $f^{c}-f^{m}$ & $\Pi$ & $D^{c}$ & $D^{m}$ & $D^{c} D^{m}$ \\
\hline 0 & 0 & 1 & 1 & .190 & .255 & -.065 & .189 & .496 & .745 & .370 \\
\hline 0 & 0.5 & 1 & 1 & .249 & .461 & -.212 & .096 & .420 & .539 & .226 \\
\hline 0 & 0 & 1 & 1 & .188 & .250 & -.062 & .184 & .489 & .750 & .367 \\
\hline 0 & 0.5 & 1 & 1 & .249 & .459 & -.210 & .093 & .412 & .541 & .223 \\
\hline
\end{tabular}

Cartel

Network 1

\begin{tabular}{|c|c|c|c|c|c|c|c|c|c|c|}
\hline$g$ & $c$ & $\mu$ & $\tau$ & $f^{c}$ & $f^{m}$ & $f^{c}-f^{m}$ & $\Pi$ & $D^{c}$ & $D^{m}$ & $D^{c} D^{m}$ \\
\hline 0.1 & 0 & 1 & 1.1 & .522 & .177 & .345 & .177 & .311 & .823 & .256 \\
\hline 0.1 & 0.5 & 1 & 1.1 & .474 & .371 & .103 & .071 & .244 & .629 & .153 \\
\hline 0.1 & 0 & 1.1 & 1.1 & .480 & .238 & .242 & .186 & .327 & .784 & .256 \\
\hline 0.1 & 0.5 & 1.1 & 1.1 & .442 & .432 & .010 & .080 & .266 & .607 & .162 \\
\hline
\end{tabular}

Network 2

\begin{tabular}{|c|c|c|c|c|c|c|c|c|c|c|}
\hline$g$ & $c$ & $\mu$ & $\tau$ & $f^{c}$ & $f^{m}$ & $f^{c}-f^{m}$ & $\Pi$ & $D^{c}$ & $D^{m}$ & $D^{c} D^{m}$ \\
\hline 0 & 0 & 1.0 & 1.0 & .349 & .265 & .084 & .225 & .413 & .735 & .304 \\
\hline 0 & 0.5 & 1 & 1 & .307 & .464 & -.157 & .104 & .363 & .536 & .195 \\
\hline 0 & 0 & 1 & 1 & .356 & .261 & .095 & .221 & .403 & .739 & .298 \\
\hline 0 & 0.5 & 1 & 1 & .311 & .461 & -.150 & .102 & .350 & .539 & .189 \\
\hline
\end{tabular}

Table 3: Asymmetric competition

Table 3 presents equilibrium prices and demand volumes under asymmetric duopolistic competition and collusion, for a variety of parameter values. The cases could be interpreted as simulating (in a rather simplistic way) competition between a debit card network (network 2) and a credit card network (network 1). The latter is assumed to have higher customer costs and to provide more benefits to consumers (such as credit) and potentially, to merchants.

The effects of competition on the asymmetric market are not qualitatively different from the ones obtained under symmetry. This should not come as a surprise, as the sign of pecuniary externalities in equations (10) and (11) were derived for the general case.

Numerical examples confirm that relative prices, both in competition and in collusion, move in opposite directions, when parameter values for one network are changed from the 
symmetric benchmark. In all circumstances, when fees on one side of the market are lowered by a network, the other network reacts by lowering fees on the opposite market side.

It can also be verified that all prices and demand volumes reported in Table 3 are consistent with the initial hypothesis of consumers selecting only one network. In other words, consumers would be free to get both cards, yet they will choose only one card here, given these consumer fees and acceptance levels by merchants.

\section{Bertrand-like competition}

Instead of assuming that benefits are independently drawn for each payment network, consider the opposite polar case of perfect correlation. For example, a consumer may value the possibility of making credit card transactions, irrespective of the type of card. Basic benefits are the same for the two payment instruments, although they are consumerspecific.

This case can be accommodated by assuming that a uniform random variable $x$ in the interval $[0,1]$ is drawn for each consumer, and basic benefits are obtained by multiplying this variable by (network-specific) maximum basic benefits $\tau_{i}$. In this case:

$$
U^{c}=\max \left\{0, x \tau_{1} D_{1}^{m}-f_{1}^{c}, x \tau_{2} D_{2}^{m}-f_{2}^{c}\right\}
$$

Again, to be chosen, a card must provide net benefits:

$$
x \tau_{i} D_{i}^{m} \geq f_{i}^{c} \Rightarrow x \geq \min \left(1, \frac{f_{i}^{c}}{\tau_{i} D_{i}^{m}}\right)
$$

and it must be better than the alternative one. Using the indifference condition:

$$
x \tau_{i} D_{i}^{m}-f_{i}^{c}=x \tau_{j} D_{j}^{m}-f_{j}^{c}
$$

we can define two sets, $[0, x]$ and $[x, 1]$, identifying the range of values of $x$, for which one network is preferred to the other.

The market share of a network is given by the intersection of this preference set and the set defined by equation (23). Of course, this intersection may be empty. There is one exception: when total maximum benefits, merchant demand and consumer fees are equal, the two market areas overlap and the consumer is indifferent between the two cards. In this case, we assume that the market is equally split.

To understand how prices are set in a symmetric duopolistic equilibrium, start from arbitrary initial fee levels. On the consumer side, total demand would then be determined by the viability condition (23). From this point on, a slight reduction in the consumer fee or, equivalently, in the merchant fee, could allow each competitor to conquer the whole market (although total demand would change only marginally). That is, each competitor has an incentive to undercut either by lowering the consumer fee or by lowering the merchant fee.

The outcome is a special type of Bertrand price war with two instruments and the equilibrium is found when profits are dissipated. Each network tries to offer higher net 
benefits to the subscribing consumers. In equilibrium, consumer net benefits are maximized with a non-negative network profit constraint. ${ }^{19}$

This result is a direct consequence of the perfect correlation in the distribution of consumer benefits. In real markets, consumers are likely to have both brand and payment instrument preferences. In terms of Figure 1, consumers would then be located inside a positively sloped 'cloud' of points, and the market equilibrium would fall somewhere in between the two polar cases - perfect correlation and independent distributions of consumer benefits.

In our model, competitor networks fight for consumers, not merchants. If products are less differentiated, competition is more intense. This translates into lower consumer prices and lower merchant prices because more affiliated merchants is one way of getting more consumers.

\section{$5 \quad$ Policy implications}

Antitrust authorities and courts in several jurisdictions have investigated the business practices of payment networks. The apparent barriers to competition in the payment card industry and its harm to consumers and merchants has been the basis for these investigations. In the United States, the Government sued MasterCard and Visa alleging anticompetitive business practices. The court ruled that MasterCard and Visa must allow financial institutions to issue competitor network credit cards such as American Express and Discover (see United States v. Visa USA, Inc., 2001).

In another U.S. case that was settled out of court, around 5 million U.S. merchants sued the two card associations alleging an illegal tying of the associations signature-based debit cards and credit cards. ${ }^{20}$ The card associations agreed to unbundle their signature-based debit card branded product from their credit card branded product.

In Australia, the Reserve Bank of Australia set rules for the determination of interchange fees, removed no-surcharge restrictions, and reduced barriers for entry to the market for credit card services (see Reserve Bank of Australia, 2002). The authorities in the European Commission and the United Kingdom have also investigated the business practices of the card associations (see European Commission, 2002 and Cruickshank, 2000). These investigations have led to the development of several theoretical models to study pricing of payment services.

However, few academic models address the issue of platform competition in the provision of payment services. We are one of the first along with Armstrong and Wright (2004) to consider competition among differentiated payment products being supplied by a single network or different networks. Our modelling strategy is justified by the coexistence of multiple payment networks that may serve various niche markets for a given payment instrument and/or supply multiple payment instruments. In this article, we address the effect of competing payment networks on consumer and merchant welfare. We find that competition unambiguously increases consumer and merchant welfare suggesting that

\footnotetext{
${ }^{19}$ A similar result is found by Guthrie and Wright (2003). In their model, however, consumers get their draw of transactional benefits after having subscribed a card. This implies that consumers are ex-ante equal, when making a subscription decision. However, Guthrie and Wright do not consider positive subscription fees.

${ }^{20}$ For a discussion of the recently settled U.S. merchant lawsuit against MasterCard and Visa, see Chakravorti (2003).
} 
policymakers should promote competition among networks providing similar products and those offering different products. Within a payment type such as credit cards, debit cards, or checks, providers offer various differentiated products. Our results suggest that not only are there benefits to competition within a payment type but also across payment types. Thus, when determining policies regarding payment networks, competitive pressures from similar and different payment products should be considered. Thus, our model can shed light upon the recent untying of credit and debit card acceptance as stipulated in the settlement of the U.S. merchant case against MasterCard and Visa. While we do not address the issue of tying in our model, we demonstrate that duopolistic competition unambiguously increases consumer and merchant welfare versus a monopolistic cartel.

For an example of the effects of competition on price level, we look to the entry of credit cards in the U.S. grocery store market. In certain market segments, such as grocery stores in the United States, the acceptance of lower cost alternatives such as PIN-based debit cards resulted in lower merchant discounts for MasterCard and Visa branded credit cards. ${ }^{21}$ During the same time, there were no noticeable differences on the consumer side. In fact, certain card issuers are offering additional benefits to those cardholders that make purchases at grocery stores. To isolate the effect of competition on price structure is a bit more difficult.

\section{Conclusion}

To date most theoretical models consider a single platform with varying levels of competition among network participants. Few theoretical models have considered competing payment platforms. Unlike previous models, we consider network-specific benefits for consumers and merchants. We investigate the impact of competing payment networks on consumer and merchant welfare, network profits, and the ratio of consumer and merchant prices. We find that competition always improves consumer and merchant welfare. As expected, network profits decrease with competition. The ratio of consumer and merchant prices depend on the differences in the benefits.

However, we ignore some aspects of the payment industry captured by others. Most notably, we ignore strategic reasons for merchants to accept other payment products. Guthrie and Wright (2003) consider intratemporal business stealing as a motivation for merchants to accept payment cards. Business stealing would affect the level of merchant fees. However, the aggregate welfare of merchants does not improve with business stealing because net sales presumably remain constant. In fact, Chakravorti and To (2003) suggest that intertemporal business stealing may decrease merchant welfare under certain conditions.

We also ignore some benefits of a single platform providing payment services or cooperation between payment networks. Payment services most likely exhibit economies of scale and scope..$^{22}$ However, as noted above, consumers and merchants may have strong preferences for product differentiation resulting in potentially restricting scale economies. Some economists have argued that certain types of governance structures may limit

\footnotetext{
${ }^{21}$ Note that the benefits to grocers from credit cards may be less than other types of merchants. Some analysts have argued that some consumers may be reluctant to make food and other "necessary" good purchases on credit. For more details, see McAndrews and Stefanadis (1999).

${ }^{22}$ For discussion of scale and scope economies in payment services, see Chakravorti and Kobor (2005).
} 
monopoly rents. Hausman, Leonard, and Tirole (2003) suggest that if the payment platforms are not-for-profit entities and are not allowed to share profits with members, cooperation among the networks may limit the rents that could be earned. We leave these issues for future research.

In reality, consumers and merchants both multihome to some extent. Unfortunately, there are difficulties in modeling an environment where consumers and merchants both multihome in the presence of fixed fees. ${ }^{23}$ In markets such as the United States where consumers carry several payment products, consumers may still prefer to use one payment instrument for most transactions. Alternatively, consumers may have preferences for one payment instrument based on the value and type of the transaction. Therefore, consumers may carry more than one card as insurance when one card is not accepted by the merchant or for some technical reason does not function. The underlying reasons why consumers multihome remains a future direction of research.

In this article, we extend the literature on payment networks that sheds light on the effects of competition on consumer and merchant welfare by considering a specific level of benefits for each consumer and merchant for each network's payment services. We find threshold values when competition affects consumer prices or merchant prices more. While there are theoretical models that investigate network competition, these models have not been empirically tested. This type of empirical research is vital for policymakers to adopt the optimal polices regarding payment networks.

\section{$7 \quad$ References}

Ahlborn, C., H.H. Chang, and D.S. Evans (2001) "The Problem of Interchange Fee Analysis: Case Without a Cause," European Competition Law Review, 22: 304-312.

Armstrong, M. (2004) "Competition in Two-Sided Markets," mimeo, University College London.

Armstrong, M. and J. Wright (2004) "Two-Sided Markets, Competitive Bottlenecks and Exclusive Contracts," mimeo, University College London and National University of Singapore.

Balto, D.A. (2000) “The Problem of Interchange Fees: Costs without Benefits," European Competition Law Review, 21: 215-224.

Baxter, W.F. (1983) "Bank Interchange of Transactional Paper: Legal and Economic Perspectives," Journal of Law \& Economics, 26: 541-588.

Caillaud, B. and B. Jullien (2001) "Chicken \& Egg: Competing Matchmakers," mimeo, IDEI and GREMAQ, University of Toulouse.

Caillaud, B. and B. Jullien (2003) "Chicken \& Egg: Competition among Intermediation Service Providers," RAND Journal of Economics, 24: 309-328.

\footnotetext{
${ }^{23}$ For a model with endogenous single/multihoming on both sides, see Roson (2005).
} 
Chakravorti, S. (2003) "Theory of Credit Card Networks: A Survey of the Literature," Review of Network Economics, 2: 50-68.

Chakravorti, S. and W.R. Emmons (2003) "Who Pays for Credit Cards?" Journal of Consumer Affairs, 37: 208-230.

Chakravorti, S. and E. Kobor (2005) "Why Invest in Payment Innovations," Journal of Payment System Law, 1: 331-353.

Chakravorti, S. and T. McHugh (2002) "Why Do We Write so Many Checks?” Federal Reserve Bank of Chicago Economic Perspectives, Third Quarter, 44-59.

Chakravorti, S. and A. Shah (2003) "The Study of the Interrelated Bilateral Transactions in Credit Card Networks," The Antitrust Bulletin, 48: 53-75.

Chakravorti, S. and T. To (2003) A Theory of Credit Cards. Mimeo, Federal Reserve Bank of Chicago.

Cruickshank, D. (2000) Competition in UK Banking: Report to the Chancellor of the Exchequer.

European Commission (2002) "Case No. Comp/29.373 - Visa International - Multilateral Interchange Fee," Official Journal of the European Communities, 2002/L318/17, November 22 .

Evans, D.S. (2003) "Some Empirical Aspects of Multi-Sided Platform Industries," Review of Network Economics, 2: 191-209.

Farrell, J. and G. Saloner (1985) "Standardization, Compatibility and Innovation," Rand Journal of Economics, 16: 70-83.

Frankel, A.S. (1998) "Monopoly and Competition in the Supply and Exchange of Money," Antitrust Law Journal, 66: 311-361.

Gans, J.S. and S.P. King (2003) "The Neutrality of the Interchange Fees in the Payment System," Topics in Economic Analysis \& Politics, 3, article 1. http://www.bepress.com/bejeap/topics/vol3/iss1/art1

Guthrie, G. and J. Wright (2003) "Competing Payment Schemes," Working Paper No. 0311, Department of Economics, National University of Singapore.

Hausman, J.A., G.K. Leonard, and J. Tirole (2003) "On Nonexclusive Membership in Competing Joint Ventures," Rand Journal of Economics, 34: 43-62.

Little, I. and J. Wright, (2000) "Peering and Settlement in the Internet: an Economic Analysis," Journal of Regulatory Economics, 18: 151-173.

Jullien, B. (2001) "Competing in Network Industries: Divide and Conquer," mimeo, IDEI and GREMAQ, University of Toulouse. 
Katz, M.L. (2001) Reform of Credit Card Schemes in Australia II. Sydney, Australia: Reserve Bank of Australia.

Katz, M.L. and C. Shapiro (1985) "Network Externalities, Competition, and Compatibility," American Economic Review, 75: 424-440.

McAndrews, J.J. and C. Stefanadis (1999) "The Issues of Exclusivity and Overlapping Governance in the Visa and MasterCard Antitrust Case," mimeo, Federal Reserve Bank of New York.

Reserve Bank of Australia (2002) Reform of Credit Card Schemes in Australia IV: Final Reforms and Regulation Impact Statement. Sydney, Australia: Reserve Bank of Australia.

Rochet, J.C., and J. Tirole (2002) "Cooperation among Competitors: The Economics of Payment Card Associations," Rand Journal of Economics, 33: 549-570.

Rochet, J.C., and J. Tirole (2003) "Platform Competition in Two-Sided Markets," Journal of European Economic Association, 1: 990-1029.

Rochet, J.C., and J. Tirole (2004) "Two-Sided Markets: An Overview," mimeo, IDEI University of Toulouse. A preliminary version was presented at "The Economics of TwoSided Markets" conference, held at the University of Toulouse, January.

Roson, R. (2003) "Incentives for the Expansion of Network Capacity in a Peering Free Access Settlement," Netnomics, 5: 149-159.

Roson, R. (2005) "Platform Competition with Endogenous Multihoming," forthcoming in Dewenter, R. and J. Haucap (ed.), Access Pricing: Theory, Practice, Empirical Evidence. Elsevier Science: Amsterdam.

Schiff, A. (2003) "Open and Closed Systems of Two-Sided Networks," Information Economics and Policy, 15: 425-442.

Schmalensee, R. (2002) "Payment Systems and Interchange Fees," Journal of Industrial Economics, 50: 103-122.

Schwartz, M. and D.R. Vincent (2002) "Same Price, Cash or Card: Vertical Control by Payments Networks," mimeo, University of Maryland.

United States v. Visa U.S.A., Inc. (2001) 163 F. Supp. 2d 322 (S.D. N.Y.).

Vis, E. and J. Toth (2000) The Abolition of the No-Discrimination Rule. ITM Research for Competition DG: Amsterdam.

Wright, J. (2003) “Optimal Card Payment Systems," European Economic Review, 47: 587612.

Wright, J. (2004) "The Determinants of Optimal Interchange Fees in Payment Systems," Journal of Industrial Economics, 52: 1-26. 